\title{
Predictive value of ATRIA risk score for contrast- induced nephropathy after percutaneous coronary intervention for ST-segment elevation myocardial infarction
}

\author{
(D) Fatih Aksoy ${ }^{1}$ \\ (iD) Ali BagCl ${ }^{2}$
}

1. MD, Associate Professor From the Department of Cardiology, Suleyman Demirel University, Medical School, Isparta, Turkey 2. MD. Physician, Department of Cardiology, Isparta Şehir Hastanesi, Isparta, Turkey.

http://dx.doi.org/10.1590/1806-9282.65.11.1384

\section{SUMMARY}

BACKGROUND: The AnTicoagulation and Risk factors In Atrial fibrillation (ATRIA) risk score used to detect the thromboembolic and hemorrhagic risk in atrial fibrillation patients has been shown recently to predict poor clinical outcomes in patients with acute myocardial infarction (ACS), regardless of having atrial fibrillation (AF). We aimed to analyze the relationship between different risk scores and contrast-induced nephropathy $(C I N)$ development in patients with ACS who underwent urgent percutaneous coronary intervention $(P C I)$ and compare the predictive ability of the ATRIA risk score with the MEHRAN risk score.

METHODS: We analyzed 429 patients having St-segment Elevation Myocardial Infarction (STEMI) who underwent urgent PCI between January 2016 and February 2017. Patients were divided into two groups: those with and those without CIN and both groups were compared according to clinical, laboratory, and demographic features, including the CHA2DS2-VASc and ATRIA risk score. Predictors of CIN were determined by multivariate regression analysis. Receiver operating characteristics (ROC) curve analysis was used to analyze the prognostic value of CHA2DS2-VASc and ATRIA risk score for CIN, following STEMI.

RESULTS: Multivariate regression analysis showed that Athe TRIA risk score, Opaque/Creatinine Clearance ratio, and low left ventricular ejection fraction was an independent predictor of CIN. The C-statistics for the ATRIA risk score and CHA2DS2-VASC risk score were 0.66 and 0.64 ( $p<0.001$, and $p<0.001)$, respectively. A pair-wise comparison of ROC curves showed that both scores were not inferior to the MEHRAN score in predicting CIN.

CONCLUSION: The ATRIA and CHA2DS2-VASC scoring systems were useful for detecting CIN following STEMI.

KEYWORDS: ATRIA risk score, St-segment Elevation Myocardial Infarction, Contrast induced nephropathy

RUNNING HEAD: The relationship between ATRIA risk score and contrast induced nephropathy

\section{INTRODUCTION}

Quick restoration of coronary blood flow in an occluded coronary artery is the fundamental aim of early ST-elevation myocardial infarction (STEMI) therapy. Primary percutaneous coronary intervention (p-PCI) is the preferred reperfusion strategy for acute STEMI patients within the first few hours after the onset of symptoms. ${ }^{1}$ However, life-threatening complications such as contrast-induced nephropathy (CIN) can be seen after p-PCI. A strong correlation between CIN and high mortality and morbidity in patients with STEMI has been shown. Additionally, these patients tend to have a long duration of hospitalization. ${ }^{2,3}$ It was shown that different clinical and laboratory variables such as contrast media volume,

DATE OF SUBMISSION: 30-Jul-2019

DATE OF ACCEPTANCE: 01-Sep-2019

CORRESPONDING AUTHOR: Fatıh Aksoy

Suleyman Demirel University - Faculty of Medicine, Cardiology Department

Isparta - Turkey - 32040 - Telephone: +90505 2313661, Fax: +90 2462324510

E-mail:dr.aksoy@hotmail.com 
presence of diabetes mellitus, chronic congestive heart failure, anemia and decreased renal perfusion were associated with CIN development. ${ }^{4}$ Patients at high risk of CIN should be administered with early prophylactic measures such as hydration to prevent CIN. Additionally, high-risk patients should be followed up for creatinine progression after the procedure. $^{2}$ Therefore, scoring systems should be developed to predict the development of CIN.

The CHA2DS2-VASc and Anticoagulation and Risk Factors in Atrial Fibrillation (ATRIA) risk scores are cheap and easy scoring systems used to predict the risk of thromboembolism in non-valvular atrial fibrillation (AF) patients. ${ }^{5,6}$ Additionally, these scoring systems have been shown to accurately predict worse clinical outcomes in patients with acute coronary syndrome regardless of having AF. ${ }^{7,8}$ Moreover, we showed that the CHA2DS2-VASC score has predicted AF following STEMI and associated with epicardial fat tissue. ${ }^{9,10}$ The components of these scoring systems, such as advanced age, presence of hypertension, presence of diabetes mellitus, low ejection fraction, and female gender have been associated with poor outcomes, including recurrent ischemic events. ${ }^{711}$

In this study, we aimed to investigate the predictive value of different thromboembolic risk scores in atrial fibrillation for the development of CIN.

\section{METHODS}

\section{Study population}

This was a prospective single-center study. The overall study population included 459 patients undergoing primary percutaneous coronary intervention diagnosis of ST-elevation myocardial infarction. The exclusion criteria included hyperthyroidism (5 patients), age <18years, end-stage renal failure (10 patients), patients treated with emergent coronary artery bypass graft surgery (10 patients), sepsis (5 patients), exposed to contrast injection within 7 days before primary percutaneous coronary intervention (30 patients), known malignancy, severe hepatic dysfunction, and inflammatory disease. Patients who presented with cardiogenic shock or died during the first 72 hours of their hospital stay, or during revascularization, were also excluded from the study. Therefore, the final study cohort consisted of 399 patients with STEMI. The study protocol was reviewed and approved by the Local Ethics Committee of the Sü- leyman Demirel University Medical School (Approval number: 72867572.050.01.04-299118) in accordance with the Declaration of Helsinki.

\section{Diagnosis of contrast-induced nephropathy}

CIN was defined as the impairment of renal function and measured as either a $25 \%$ increase in serum creatinine from the baseline or a $0.5 \mathrm{mg} / \mathrm{dL}$ increase in the absolute value when there was no alternative etiology within 72 hours of the first procedure ${ }^{4}$. Creatinine Clearance was calculated using the Cockcroft-Gault Equation. ${ }^{12}$

\section{Diagnosis of thromboembolic risk}

The $\mathrm{CHA}_{2} \mathrm{DS}_{2}$-VASc risk score is calculated by assigning a score of 1 point for each of the following conditions: congestive heart failure (ejection fraction< 40\%), hypertension, age between 65 and 74 years, diabetes mellitus, vascular disease (myocardial infarction or peripheral arterial disease), and female gender; a score of 2 points for the following conditions: history of stroke or transient ischemic attack (TIA) and age $>75$ years. The score is then used to predict the risk of thromboembolism in non-valvular AF patients. ${ }^{5}$

The ATRIA score was developed from the ATRIA study cohort and calculated using the following: anemia (hemoglobin $<13 \mathrm{~g} / \mathrm{dL}$ in men and $<12 \mathrm{~g} / \mathrm{dL}$ in women) (3 points), severe renal disease (estimated glomerular filtration rate $\left.<30 \mathrm{~mL} / \mathrm{min} / 1.73 \mathrm{~m}^{\wedge} 2\right)(3$ points), age $\geq 75$ years ( 2 points), prior bleeding, and hypertension. An ATRIA score of 0 to 3 is defined as "low risk," a score of 4 is defined as "intermediate risk," and a score $\geq 5$ is defined as "high risk". ${ }^{6}$

\section{Diagnosis of STEMI}

Diagnoses were recorded by the participating physicians based on clinical, electrocardiographic and biochemical (elevated troponin levels) criteria. The type of myocardial infarction (ST-elevation vs. non-ST-elevation) and unstable angina were homogeneously defined based on current guidelines. All patients were treated according to the currently available guidelines. Primary percutaneous coronary intervention (PCI) was performed in all patients. ${ }^{13}$

\section{Blood sampling}

Blood samples were drawn from the antecubital vein by careful venipuncture using a $21 \mathrm{G}$ sterile syringe without stasis between 08.00-10.00 AM after 
a fasting period of $12 \mathrm{~h}$. Glucose, creatinine, and lipid profiles were determined by standard methods. Hemogram parameters were measured in a blood sample collected in dipotassium EDTA tubes (Vacuette). An automatic blood counter (Beckman-Coulter Co, Miami, FL, USA) was used for whole blood counts.

\section{STATISTICAL ANALYSIS}

SPSS version 16.0 software package was used for statistical analyses in this study. Categorical variables were expressed as frequency (\%) and compared using the $\chi 2$ test. Kolmogorov-Smirnov test was used to test the distribution of numeric variables; those with normal distribution were expressed as mean \pm standard deviation and compared with Student's t-test. Data without normal distribution were expressed as median (Inter-quartile range (IQR) of 25\%$75 \%$ percentiles) and compared with the Mann-Whitney U test. In all statistical analyses, a p-value $<0.05$ was considered statistically significant. The correlations between the CHA2DS2-VASc and ATRIA risk scores, CIN and other clinical, laboratory, and echocardiographic parameters were measured by Pearson or Spearman correlation analysis when appropriate. Univariate analysis and backward conditional binary logistic regression were performed to estimate the odds ratio (OR) and 95\% confidence interval (95\% CI) for the prediction of CIN. Receiver operating characteristics (ROC) curve analysis was used to analyze the prognostic value of the CHA2DS2-VASc and ATRIA risk scores for CIN, following STEMI. C-Statistic (area under the curve) was presented as a unified estimate of sensitivity and specificity according to the cutoff value that was obtained by the ROC curve analysis. The optimal cutoff value was defined as the value yielding the maximal Youden index, or the best-combined sensitivity and specificity. ${ }^{14}$ All ROC comparisons were performed using the DeLong test. ${ }^{15} \mathrm{C}$-Statistic (area under the curve) was presented as a unified estimate of sensitivity and specificity.

\section{RESULTS}

A total of 399 patients (mean age: $63 \pm 11$ years; range, 28-91 years) were included in this study. During the follow-up period, 88 patients (22\%) developed CIN. The demographic and clinical characteristics of the patients with and without CIN are listed in Table 1 . The patients with CIN were significantly older and more often female when compared to the patients without CIN $(p<0.001$ and $p=0.015$, respectively). Diabetes mellitus, hypertension, obesity, and hyperlipidemia rates were similar between patients with and without CIN (for all parameters p> 0.05). There were no statistically significant differences between patients with and without CIN with regards to cholesterol parameters (for all parameters p>0.05). Left ventricle ejection fraction was significantly lower in patients with CIN than in patients without CIN ( $p=0.016)$. Initial creatinine levels were similar between patients with and without CIN, but the 72hour creatinine levels were higher in patients with CIN than in patients without $\operatorname{CIN}(p<0.001)$

The incidence of previous use of renin-angiotensin system (RAS) blockers was lower in patients with CIN than in patients without CIN $(p=0.055)$. There were no statistically significant differences between patients with and without CIN with regards to the use of beta-blockers, acetylsalicylic acid, clopidogrel, or statins. Among in-hospital treatments, the use of RAS blockers was lower in patients with CIN ( $\mathrm{p}=$ 0.003), but other medications were similar among patients with and without CIN ( $p>0.05)$. Patients with CIN had a longer period of stay at the Coronary Care Unit and a longer follow-up duration than patients without $\mathrm{CIN}(2.2 \pm 0.7$ versus $2.0 \pm 0.4 ; \mathrm{p}=0.02$ and $6.0 \pm 2.2$ versus $5.1 \pm 1.7 ; p<0.001$, respectively).

The mean CHA2DS2-VASc, ATRIA, and MEHRAN scores were significantly higher in patients with CIN than in patients without $\operatorname{CIN}(2.6 \pm 1.4$ versus $1.9 \pm 1.4$, $\mathrm{p}<0.001 ; 4.3 \pm 2.7$ versus $3.1 \pm 2.7, \mathrm{p}<0.001 ; 5.3 \pm 2.7$ versus $4.3 \pm 2.7, p<0.001$; respectively).

\section{Prediction of Contrast-induced nephropathy}

Univariate analyses showed that high CHA2DS2VASc and ATRIA risk scores, low left ventricle ejection fraction, advanced age, opaque amount, opaque amount/Creatinine Clearance ratio, and female gender were significantly associated with a higher risk of development of CIN (Table 2). On the other hand, pre and in-hospital use of RAS blockers were inversely associated with the risk of incident CIN (Table 2).

A multivariate binary logistic regression analysis was carried out, including all characteristics that were associated with the development of CIN in the univariate analysis. This analysis showed that the opaque amount/Creatinine Clearance ratio (OR: 1.22; 95 \% CI: 1.00-1.50, $\mathrm{p}=0.04$ ), ATRIA score (OR: 1.12; $95 \% \mathrm{CI}: 1.00-1.25, \mathrm{p}=0.04)$ and left ventricle ejection 
TABLE 1. DEMOGRAPHIC AND CLINICAL CHARACTERISTICS OF PATIENTS WITH AND WITHOUT CONTRASTINDUCED NEPHROPATHY

\begin{tabular}{|c|c|c|c|}
\hline \multicolumn{4}{|c|}{ Contrast-Induced Nephropathy } \\
\hline & No $(n=311)$ & Yes $(n=88)$ & P-value \\
\hline Female gender $\mathrm{n},(\%)$ & 59 (19.9) & $28(31.8)$ & 0.015 \\
\hline Diabetes Mellitus n, (\%) & $71(23.9)$ & $27(30.7)$ & 0.127 \\
\hline Hypertension n, (\%) & $142(47.8)$ & $48(54.5)$ & 0.161 \\
\hline Hyperlipidemia n, (\%) & $57(19.2)$ & $19(21.6)$ & 0.360 \\
\hline Age (years) & $61.4 \pm 13$ & $67.9 \pm 9$ & $<0.001$ \\
\hline \multicolumn{4}{|l|}{ Previous treatment } \\
\hline RAS blockers n, (\%) & $45(15.2)$ & $7(8.0)$ & 0.055 \\
\hline B Blockers n, (\%) & $47(15.8)$ & $10(11.4)$ & 0.127 \\
\hline Statins n, (\%) & $31(10.4)$ & $10(11.4)$ & 0.469 \\
\hline \multicolumn{4}{|l|}{ In hospital Treatment } \\
\hline RAS blockers n, (\%) & $248(83.5)$ & $61(69.3)$ & 0.003 \\
\hline B Blockers n, (\%) & $275(92.6)$ & $86(97.7)$ & 0.07 \\
\hline Statins n, (\%) & $292(98.3)$ & $87(98.9)$ & 0.585 \\
\hline Left ventricle ejection fraction (\%) & $45.8 \pm 9.5$ & $42.5 \pm 10$ & 0.016 \\
\hline CHA2DS2-VASc Risk score & $1.9 \pm 1.4$ & $2.6 \pm 1.4$ & $<0.001$ \\
\hline ATRIA Risk Score & $3.1 \pm 2.7$ & $4.3 \pm 2.7$ & $<0.001$ \\
\hline Opaque amount (cc) & $124 \pm 38$ & $169 \pm 44$ & $<0.001$ \\
\hline Opaque/CrCl ratio & $1.9 \pm 1.3$ & $2.8 \pm 1.4$ & $<0.001$ \\
\hline Mehran Risk Score & $4.3 \pm 3.7$ & $5.3 \pm 2.7$ & $<0.001$ \\
\hline Initial creatinine (mg/dl) & $1.1 \pm 0.3$ & $1.0 \pm 0.2$ & 0.168 \\
\hline 72th hour creatinine (mg/dl) & $1.1 \pm 0.3$ & $1.5 \pm 0.5$ & $<0.001$ \\
\hline Duration of CCU stay (day) & $2.0 \pm 0.4$ & $2.2 \pm 0.7$ & 0.02 \\
\hline Total Hospitalization stay (day) & $5.1 \pm 1.7$ & $6.0 \pm 2.2$ & $<0.001$ \\
\hline
\end{tabular}

Data presented as mean \pm standart deviation or number (\%) of patients. Abbreviations: RAS = renin-angiotensin system; CHA2DS2-VASc= congestive heart failure, hypertension, age $\geq 75$ years, diabetes mellitus, previous stroke, vascular disease, age 65 to 74 years, female gender; ATRIA - Anticoagulation and Risk Factors in Atrial Fibrillation Risk Score; CrCl: Creatinine Clearance, CCU: Coronary care unit

TABLE 2. UNIVARIATE AND MULTIVARIATE REGRESSION ANALYSIS OF PREDICTORS OF CONTRAST-INDUCED NEPHROPATHY IN THE STUDY POPULATION.

\begin{tabular}{|c|c|c|c|c|c|c|}
\hline & $\begin{array}{l}\text { Unadjusted } \\
\text { Odds Ratio }\end{array}$ & Confidence interval & P-value & $\begin{array}{l}\text { Adjusted } \\
\text { Odds Ratio }\end{array}$ & $\begin{array}{l}\text { Confidence } \\
\text { interval }\end{array}$ & P-value \\
\hline Female gender & 1.88 & $1.1-3.2$ & 0.02 & & & \\
\hline $\begin{array}{l}\text { Left ventricle ejection } \\
\text { fraction }\end{array}$ & 0.96 & $0.94-0.99$ & 0.007 & 0.97 & $0.95-1.00$ & 0.09 \\
\hline Previous ACEi using & 2.0 & $0.89-4.76$ & 0.08 & & & \\
\hline In-hospital ACEi using & 2.2 & $1.29-3.87$ & 0.004 & & & \\
\hline $\begin{array}{l}\text { CHA2DS2-VASc Risk } \\
\text { score }\end{array}$ & 1.3 & $1.17-1.63$ & $<0.001$ & & & \\
\hline $\begin{array}{l}\text { High CHA2DS2-VASC } \\
\text { group }\end{array}$ & 2.7 & $1.57-4.70$ & $<0.001$ & & & \\
\hline ATRIA Risk Score & 1.16 & $1.07-1.27$ & $<0.001$ & 1.12 & $1.00-1.25$ & 0.04 \\
\hline Opaque amount & 1.024 & $1.01-1.03$ & $<0.001$ & & & \\
\hline Opaque/CrCl ratio & 1.44 & $1.22-1.70$ & $<0.001$ & 1.22 & $1.00-1.50$ & 0.04 \\
\hline Mehran Risk Score & 1.13 & $1.06-1.20$ & $<0.001$ & & & \\
\hline
\end{tabular}

fraction (OR: 0.97; 95 \% CI: 0.95-1.00, p= 0.09) remained as independent factors for CIN development (Table 3). the ROC curve analysis showed that both ATRIA (C-statistic: 0.66; 95\% CI: 0.61-0.71, p< 0.001) and CHA2DS2-VASc scores (C-statistic: 0.64; 95\% CI: 0.59-0.76, $\mathrm{p}<0.001)$ were significant predictors of
CIN following STEMI (Figure 1) We calculated that a cut-off point of 2 for ATRIA and CHA2DS2-VASc scores could estimate the presence of CIN with a sensitivity of $72 \%$ and $55 \%$ and a specificity of $54 \%$ and $68 \%$, respectively. Additionally, the ROC curve analysis showed that the opaque amount/Creatinine 
FIGURE 1. ROC CURVE WITH CALCULATED AREA UNDER THE CURVE AND OPTIMAL CUT-OFF POINT FOR THE CHA2DS2-VASC SCORE AND ATRIA SCORE TO IDENTIFYTHE PRESENCE OF CIN.

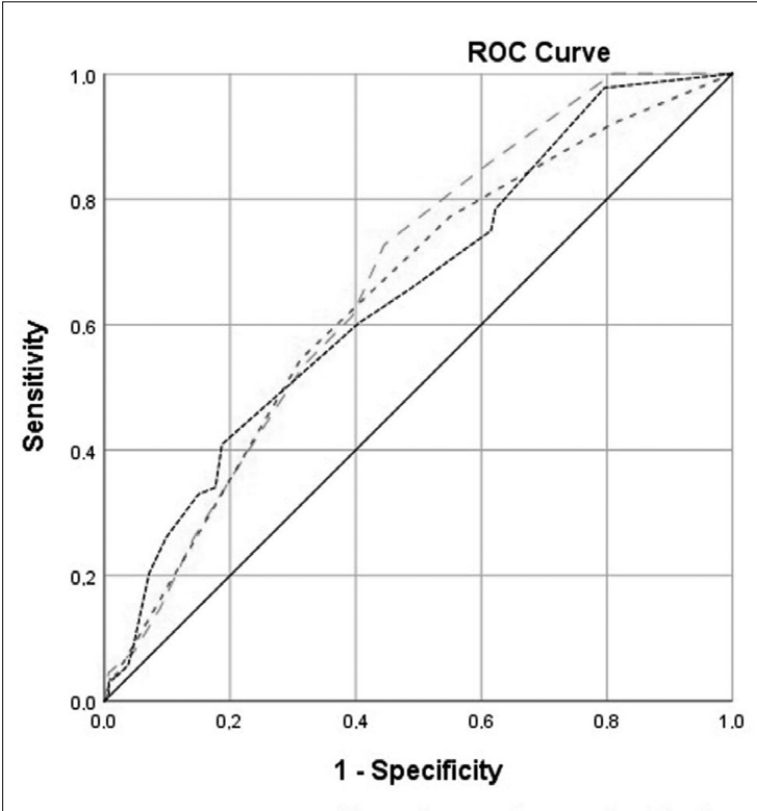

Diagonal segments are produced by ties.

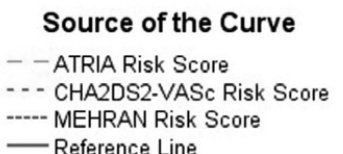

Clearance ratio (C-statistic: 0.70; 95\% CI: 0.66-0.75, $\mathrm{p}<0.001)$ was a significant predictor of CIN following STEMI. We performed a pair-wise comparison of ROC curves, and recorded that the predictive value of the ATRIA risk score with regard to CIN development was similar to that of the MEHRAN risk, CHA2DS2-VASc, and ATRIA risk scores (by DeLong method, AUC ATRIA vs. AUC MEHRAN z test $=0.712$, $\mathrm{p}=0.476$; AUC ATRIA vs. AUC CHA2DS2-VASc $\mathrm{z}$ test= $0.813, p=0.07$; AUC MEHRAN vs. AUC CHA2DS2VASc $\mathrm{z}$ test $=0.238, \mathrm{p}=0.812$ )

\section{DISCUSSION}

The current study showed that higher CHA2DS2VASc and ATRIA scores were independently associated with the development of CIN in STEMI patients treated with p-PCI; consequently, both scores could be helpful and appropriate scoring systems for predicting CIN after STEMI treated with p-PCI. Additionally, the opaque amount/Creatinine Clearance ratio is a powerful predictor of CIN development.
CIN is a serious complication of p-PCI after STEMI and is associated with worse clinical outcomes, such as prolonged length of hospital stays, rising costs, and increased short- and long-term morbidity and mortality. ${ }^{2,3}$ It is important to anticipate which patients may develop CIN. There are several risk scores that have been established to predict CIN development. ${ }^{4,16,17}$ The MEHRAN score, created for predicting $\mathrm{CIN},{ }^{4}$ includes physical examination, laboratory tests, and various demographic and angiographic parameters. Additionally, Gurm et al. ${ }^{16}$ defined a new model for predicting CIN after PCI. However, similar to the MEHRAN score, this score is complex and time-consuming as it also requires clinical and laboratory variables that may not be available to the clinician immediately. Therefore, these scoring systems are confusing and impractical due to their plurality and lack of ease of use. Conversely, the CHA2DS2VASc and ATRIA scores are simple and easy scoring systems and may be used for predicting CIN in patients with STEMI before the procedure.

Although the underlying mechanisms of CIN are not entirely understood ${ }^{18,19}$, previous studies have shown that renal vasoconstriction, endothelial dysfunction, and endothelial damage contribute to the process of CIN development by renal tubular injury and medullary hypoxia. ${ }^{20}$ Diabetes mellitus, hypertension, advanced age, congestive heart failure, volume depletion, myocardial infarction, renal dysfunction are the most important risk factors for CIN development. ${ }^{4,21-23}$ The risk factors of CIN are similar to the components of the CHA2DS2-VASc and ATRIA risk scores. ${ }^{4}$ Furthermore, these scores can be used to predict the risk of CIN. Kurtul et al ${ }^{8}$ showed that the CHA2DS2-VASc score can be used as a simple and useful tool for predicting CIN in patients with acute coronary syndrome (ACS). The data of the current study corroborate the results of Kurtul et al. Additionally, we showed that the ATRIA score can also be used to predict CIN following STEMI. Moreover, not only was the ATRIA score more powerful than the CHA2DS2-VASc score in predicting CIN, it was found to be non-inferior to the MEHRAN score in predicting CIN.

In the present study, female gender, low ejection fraction, opaque amount, opaque/eGFR ratio were risk factors for the development of CIN. Previous studies have also shown similar results. ${ }^{8,24,25}$ Contrast volume and basal renal insufficiency are important risk factors for $\mathrm{CIN}^{19}$ accordingly, the 
opaque/eGFR ratio is a good indicator for CIN. ${ }^{25}$ Our study also indicated that opaque/eGFR ratio was a powerful predictor of CIN development.

Patients at high risk of CIN should be managed with early additional measures to prevent CIN. Although there are different established scoring systems to predict CIN risk, most of these include clinical, biological, and variables that can only be obtained after invasive interventions not available pre-procedure. However, the ATRIA and CHA2DS2-VASc scoring systems can be evaluated at the first contact with a physician. Additionally, measures such as hydration may be administrated to high-risk patients, who also should be followed up for creatinine progression after the procedure.

Importantly, this study has some limitations. First, it had a relatively small sample size and engaged in a single-center experience. Second, we have only estimated our model performance in a derivation cohort, while data for a confirmation cohort are lacking. Third, we did not follow up with major adverse cardiovascular events data. Our results should, therefore, be verified by future multi-center prospective longitudinal studies with larger sample sizes. The limitations of this study should be considered while interpreting these results.

\section{CONCLUSION}

We have shown in the current study that the ATRIA and CHA2DS2-VASc scoring systems were useful for detecting CIN following STEMI. Additionally, when the ATRIA risk score was compared with previously well-validated scores, it was found to be similar in power for predicting the development of CIN. Patients at high risk, according to the ATRIA and CHA2DS2-VASc scoring systems, should be followed up for creatinine progression after the procedure and administrated intravenous hydration before the procedure.

\section{RESUMO}

OBJETIVO: O escore Anticoagulação e Fatores de Risco na Fibrilação Atrial (Atria), usado na detecção do risco tromboembólico e hemorrágico de pacientes com fibrilação atrial (FA), recentemente demonstrou predizer resultados clínicos ruins em pacientes com infarto agudo do miocárdio (SCA), independentemente de ter FA. Nosso objetivo foi analisar a relação entre os diferentes escores de risco e o desenvolvimento de nefropatia induzida por contraste (NIC) em pacientes com SCA submetidos à intervenção coronária percutânea (ICP) urgente e comparar a capacidade preditiva do escore de risco Atria com o escore de risco Mehran.

MÉTODOS: Foram analisados 429 pacientes com infarto agudo do miocárdio com elevação do segmento ST (IAM-ST) submetidos à ICP de urgência entre janeiro de 2016 e fevereiro de 2017. Os pacientes foram divididos em dois grupos: aqueles com e sem NIC, e ambos os grupos foram comparados de acordo com as características clínicas, laboratoriais e demográficas, incluindo os escores de risco CHA2DS2VASc e Atria. Preditores de NIC foram determinados por análise de regressão multivariada. A análise da curva características de operação do receptor (ROC) foi utilizada para analisar o valor prognóstico dos escores de risco CHA2DS2-VASc e Atria para NIC, após IAM-ST.

RESULTADOS: A análise de regressão multivariada mostrou que o escore de risco Atria, a relação opaca/crCl e a baixa fração de ejeção do ventrículo esquerdo foram preditores independentes de NIC. A estatística-C para o escore de risco Atria e o escore de risco CHA2DS2VASC foi de 0,66 e 0,64 ( $p<0,001$ e p<0,001), respectivamente. Uma comparação de pares de curvas características de operação do receptor mostrou que ambos os escores foram não inferiores ao escore Mehran na previsão de NIC.

CONCLUSÃO: Os sistemas de pontuação Atria e CHA2DS2-VASC foram sistemas úteis para a detecção de NIC após IAM-ST.

PALAVRAS-CHAVE: Escore de risco Atria. Infarto do miocárdio com elevação do segmento ST. Nefropatia induzida por contraste.

\section{REFERENCES}

1. Neumann F-J, Sousa-Uva M, Ahlsson A, Alfonso F, Banning AP, Benedetto U, Byrne RA, Collet J-P, Falk V, Head SJ, Jüni P, Kastrati A, Koller A, Kristensen SD, Niebauer J, Richter DJ, Seferović PM, Sibbing D, Stefanini GG, Windecker S, Yadav R, Zembala MO et al. 2018 ESC/EACTS Guidelines on myocardial revascularization. European Heart Journal. 2018:ehy394-ehy394.

2. Gupta R, Gurm HS, Bhatt DL, Chew DP, Ellis SG. Renal failure after percutaneous coronary intervention is associated with high mortality. Catheterization and cardiovascular interventions. 2005;64(4):442-448.

3. Liss $P$, Persson P, Hansell P, Lagerqvist B. Renal failure in 57925 patients undergoing coronary procedures using iso-osmolar or low-osmolar contrast media. Kidney international. 2006;70(10):1811-1817.

4. Mehran R, Aymong ED, Nikolsky E, Lasic Z, Iakovou I, Fahy M, Mintz GS,
Lansky AJ, Moses JW, Stone GW. A simple risk score for prediction of contrast-induced nephropathy after percutaneous coronary intervention: development and initial validation. Journal of the American College of Cardiology. 2004:44(7):1393-1399.

5. Kirchhof $P$, Benussi $S$, Kotecha D, Ahlsson A, Atar D, Casadei B, Castella M, Diener H-C, Heidbuchel H, Hendriks J. 2016 ESC Guidelines for the management of atrial fibrillation developed in collaboration with EACTS. Eur Heart J. 2016;37(38):2893-2962.

6. Singer DE, Chang Y, Borowsky LH, Fang MC, Pomernacki NK, Udaltsova N, Reynolds K, Go AS. A new risk scheme to predict ischemic stroke and other thromboembolism in atrial fibrillation: the ATRIA study stroke risk score. Journal of the American Heart Association. 2013;2(3):e000250. 
7. Çetinkal G, Koçaş C, Koçaş BB, Arslan Ş, Abacı O, Karaca OŞ, DalgıçY, Ser ÖS, Keskin K, Yıldız A. Comparative performance of AnTicoagulation and Risk factors In Atrial fibrillation and Global Registry of Acute Coronary Events risk scores in predicting long-term adverse events in patients with acute myocardial infarction. Anatolian journal of cardiology. 2018;20(2):77.

8. Kurtul A, Yarlioglues M, Duran M. Predictive value of CHA2DS2-VASC score for contrast-induced nephropathy after percutaneous coronary intervention for acute coronary syndrome. The American journal of cardiology. 2017;119(6):819-825.

9. Aksoy F, Guler S, Kahraman F, Oskay T, Varol E. The Relation Between Echocardiographic Epicardial Fat Thickness and CHA2DS2-VASc Score in Patients with Sinus Rhythm. Brazilian journal of cardiovascular surgery. 2019;34(1):41-47.

10. Aksoy F, Bas HA, Bagci A, Oskay T. The CHA2DS2-VASc score for predicting atrial fibrillation in patients presenting with ST elevation myocardial infarction: prospective observational study. Sao Paulo Med J. 2019.

11. Bozbay M, Uyarel H, Cicek G, Oz A, Keskin M, Murat A, Yildirim E, Karaca G, Ergelen M, Eren M. CHA2DS2-VASc score predicts in-hospital and longterm clinical outcomes in patients with ST-segment elevation myocardial infarction who were undergoing primary percutaneous coronary intervention. Clinical and Applied Thrombosis/Hemostasis. 2017;23(2):132-138.

12. Cockcroft DW, Gault H. Prediction of creatinine clearance from serum creatinine. Nephron. 1976;16(1):31-41.

13. Thygesen $K$, Alpert JS, Jaffe AS, Simoons ML, Chaitman BR, White HD, Infarction WGobotJEAAWTFftUDoM, Chairpersons ATFM, Thygesen K, Alpert JS. Third universal definition of myocardial infarction. European heart journal. 2012;33(20):2551-2567.

14. Youden WJ. Index for rating diagnostic tests. Cancer. 1950;3(1):32-35.

15. DeLong ER, DeLong DM, Clarke-Pearson DL. Comparing the areas under two or more correlated receiver operating characteristic curves: a nonparametric approach. Biometrics. 1988:837-845.

16. Gurm HS, Seth M, Kooiman J, Share D. A novel tool for reliable and accurate prediction of renal complications in patients undergoing percutaneous coronary intervention. Journal of the American College of Cardiology. 2013;61(22):2242-2248.

17. Liu Y-H, Jiang L, Duan C-Y, He P-C, Liu Y, Tan N, Chen J-Y. Canada Acute Coronary Syndrome Score: a preprocedural risk score for contrast-induced nephropathy after primary percutaneous coronary intervention. Angiology. 2017;68(9):782-789.

18. Detrenis S, Meschi M, Musini S, Savazzi G. Lights and shadows on the pathogenesis of contrast-induced nephropathy: state of the art. Nephrology Dialysis Transplantation. 2005;20(8):1542-1550.

19. Persson PB, Hansell P, Liss P. Pathophysiology of contrast medium-induced nephropathy. Kidney international. 2005;68(1):14-22.

20. P Basile D, C Yoder M. Renal endothelial dysfunction in acute kidney ischemia reperfusion injury. Cardiovascular \& Haematological Disorders-Drug Targets (Formerly Current Drug Targets-Cardiovascular \& Hematological Disorders). 2014;14(1):3-14.

21. Lucreziotti S, Centola M, Salerno-Uriarte D, Ponticelli G, Battezzati PM, Castini D, Sponzilli C, Lombardi F. Female gender and contrast-induced nephropathy in primary percutaneous intervention for ST-segment elevation myocardial infarction. International journal of cardiology. 2014;174(1):37-42.

22. Han X-f, Zhang X-x, Liu K-m, Tan H, Zhang Q. Contrast-induced nephropathy in patients with diabetes mellitus between iso-and low-osmolar contrast media: a meta-analysis of full-text prospective, randomized controlled trials. PloS one. 2018;13(3):e0194330.

23. Rear R, Bell RM, Hausenloy DJ. Contrast-induced nephropathy following angiography and cardiac interventions. Heart. 2016;102(8):638-648.

24. Çınar T, Tanık VO, Aruğaslan E, Karabağ Y, Çağdaş M, Rencüzoğulları I, Keskin M. The association of PRECISE-DAPT score with development of contrast-induced nephropathy in patients with ST-elevation myocardial infarction undergoing primary percutaneous coronary intervention. Cardiovascular intervention and therapeutics. 2018:1-9.

25. Nozue T, Michishita I, Iwaki T, Mizuguchi I, Miura M. Contrast medium volume to estimated glomerular filtration rate ratio as a predictor of contrast-induced nephropathy developing after elective percutaneous coronary intervention. Journal of cardiology. 2009;54(2):214-220. 